\title{
Sign of 'Cross-Vergence' in Global HRM-CSR? The UK and Japan Compared
}

\author{
William II-kuk Kang \\ Additional information is available at the end of the chapter \\ http://dx.doi.org/10.5772/intechopen.78400
}

\begin{abstract}
This chapter is designed to explore and understand corporate social responsibility (CSR)human resource management (HRM) practices in the UK and Japan (countries that have very different societal and cultural characteristics) from a national business system (NBS) perspective, in order to answer the following two questions: (a) the extent of convergence/ divergence of CSR-HRM of two very different NBSs and (b) the institutional relations behind the convergence/divergence. The chapter argues that, as a result of increasing international competition and pressure from globalization, both institutional settings and societal-cultural norms have been affected, which have transformed their traditional HRM into a new 'hybrid' form of HRM, showing signs of 'cross-vergence'. This chapter adopts a qualitative approach with comparative multiple case analysis. Three companies from each country are selected as representative cases of each business system.
\end{abstract}

Keywords: corporate social responsibility, national business system, human resource management

\section{Introduction}

Due to the Global Financial Crisis, globalization, and the recent anti-globalization movements in the USA and the UK, the global social, political, and economic environments are in turmoil. As a result, business organizations are now faced with greater challenges than ever before, one of which is how they organize and manage their employees. Following an institutional-based view, employees are one of the primary stakeholders in an organization, and organizations should fulfill their moral obligations to them by meeting their expectations [1, 2]. A resourcebased perspective sees employees as scarce and valuable resources, which are key elements to 
achieving competitive advantage [3]. Thus, given the concerns associated with the aging population and 'responsible competition' as a key agenda for business, long-term, sustainable human resource management (HRM) practices have become much more important and are transitioning dynamically $[3,4]$. A clear indication of this change is the spread of corporate social responsibility (CSR). This is a multidisciplinary concept that addresses both implicit and explicit aspects of organizations in order to achieve sustainable and socially responsible businesses. With the growing interest in CSR, there have been efforts to explore the relations between CSR and HRM [5-9]. However, given that CSR is a global phenomenon, its impact on the possible convergence or divergence of Eastern and Western CSR-HRM relations has been neglected. This chapter, therefore, explores the extent to which HRM practices are converging or diverging as a result of CSR, through comparison of two leading CSR nations, one Western and one Eastern.

From an institutional viewpoint, convergence occurs due to the increased global societal pressure from globalization and rapid technological advances. Mimetic, coercive, and normative forces cause organizations and institutions to converge and become homogenous, regardless of national boundaries [10-16]. Following this argument, various international CSR consultancies, notably UN Global Compact, the Global Reporting Initiative (GRI), and ISO 26000, have exerted pressure on institutions and organizations to cause isomorphism in management practice and show convergence [17]. This may be logical, but it is also important to consider existing differences in cultural and societal values. The national business system (NBS) theory argues that institutions are historically grown and thus have societal and cultural values embedded in them $[18,19]$. Such differences in institutional frameworks at the national level cause distinctive business systems to emerge and create divergence in firms' management practices, including CSR. This chapter intends to contribute to the existing convergence/divergence debate through comparisons of CSR-HRM practices in the UK and Japan. Wang and Juslin [20] argue that CSR is a Western concept, designed to support and fit into a Western context and thus a poor fit with the Chinese business system. Matten and Moon's [21] comparative study of explicit and implicit CSR in Europe and the USA also shows diversity in implicit CSR within Western business systems, while Jamali and Neville [22] show 'cross-vergence' of CSR management in a Lebanese context. Based on the empirical evidence from the existing literature, therefore, a comparative study of Eastern and Western nations' CSR-HRM relations can certainly contribute to the existing convergence/divergence debate.

For this purpose, Japan and the UK are selected. Despite much previous research on Japanese management and its HRM in international business, the fact that two nations share very different NBSs (compartmentalized vs. highly coordinated) and societal-cultural backgrounds (individualism vs. collectivism) [23, 24] is difficult to ignore. Furthermore, while they are understood as leading CSR contributors [20, 25], they both participate in various Westerndeveloped global CSR institutions, such as UN Global Compact, GRI, and ISO 26000. Therefore, the two nations provide ideal comparative contexts to explore the extent of convergence/divergence in CSR-HRM. The NBS is adopted as a theoretical scope for the comparison because of its quality in pointing out historically grown institutional frameworks, which also include societal-cultural institutions that influence businesses that operate within it $[18,23]$. It acknowledges the institutional differences between nations and business systems and further allows the comparison of two nations by identifying key points of contrast between the business systems [21]. Therefore, it is particularly useful in cross-national comparison, in contrast 
to institutional theory, which shows weakness in explaining how practices are interpreted elsewhere [26]. Thus, it can be understood as an ideal model with which to measure the extent of convergence/divergence of CSR-HRM in the two nations.

\section{Literature review}

\subsection{CSR and HRM}

CSR emphasizes organizational responsibility in regard to society and stakeholders and its role in social development and sustainability [27-32]. Due to its lack of a framework and philosophical and conceptual underpinning, many studies have focused on clarifying the extent of responsibilities and business performance (see [29, 33, 34]). Nonetheless, the major CSR doctrine accepted in the empirical realm seems to be an integrative approach regardless of the long-lasting debate, which promotes the integration of ethical responsibilities into corporate organizations' economic responsibilities [29,33]. This concept of integrative theories of CSR is well presented in the following definition of CSR:

Context-specific organisational actions and policies that take into account stakeholders' expectations and the triple bottom line of economic, social, and environmental performance. ([34], p. 933)

From this perspective, organizations have to consider stakeholders' expectations, while being mindful of the triple bottom line. Stakeholders are identified as 'any group of individuals who can affect or is affected by the achievement of the organisation's objectives' ([2], p. 120), which includes those in direct moral obligation relations (normative) and those that can affect the normative stakeholders (derivative). Based on this logic, HRM and CSR are highly interrelated. Employees are considered normative stakeholders due to their direct relations with organizations and their ability to influence business outcomes. Following the multilevel analysis suggested by Aguinis and Glavas [34], employees can predict, moderate, and mediate organizations' social responsible practices at an individual level, while perceiving, evaluating, judging, and reacting to firms' CSR practices as stakeholders [5, 6]. In addition, stakeholder theory's moral obligation suggests that firms should ensure the quality of employees' working life (job quality, work-life quality, and working life) as well as labor standards and equal opportunities [7]. Further evidence also suggests that responsible companies can appear more attractive to potential employees, resulting in competitive advantage $[35,36]$ and employees more committed to, and satisfied with, their jobs [37].

Therefore, based upon the existing literature, it is clear that CSR and HRM are highly interdependent and interconnected. Socially responsible HRM practices and HR practices can promote firm's CSR practices and vice versa, which affects CSR and HR outcomes that are also interrelated [7]. This suggests that by adopting socially responsible HRM practices, organizations can achieve competitive advantage, and through combining CSR and HRM, longterm sustainability is achieved [38]. In this study, socially responsible HRM practices can be achieved through three institutional frameworks, based on the NBS institutional framework. First is systematic communication with employees to understand employees' needs and promote employee participation and engagement in an organization's CSR efforts [7]. Second is training, which can create ethical labor standards. Inyang et al. [39] found that the higher level 
of incorporation of CSR objectives into training programs will lead to greater response rates from employees, and their perceptions toward the importance of CSR are likely to increase when they are trained on CSR policy and projects. Third is diversity management to promote equal opportunities. As our society is growing to become more multicultural than before, diversity management is increasingly important in organizations [40]. Therefore, diversity, responsibility and HRM should not be considered separately but as key components of organizations' CSR efforts [41].

While much of the existing literature notes that socially responsible HRM can lead to increased productivity, improved efficiency, and increased firm value [3,42-45], there is also some evidence that suggests diverse HRM models in international business. As a result of globalization, multinational corporations (MNCs) have become normalized. During the process of internationalization, organizations are faced with a new challenge, taking local conditions into account, causing tension between global and local approaches. In the case considered by Buckley and Horn [46], Japanese firms were required to alter their business models to fit local conditions in China. This shows that the previous approach of adopting the 'best practice model' is no longer a viable strategic choice for MNCs but rather creating a 'best fit' model through integration and combination, which causes diversity in HRM practices at an international level [47-49]. Stavrou's [48] study on HRM and firm performance in Europe from the NBS perspective shows that there are certain differences in HRM practices based on their business systems. This further indicates that application of Western models of CSR to East Asian companies may not result in the same outcome but rather adopting the core concept of CSR into their existing business models, causing possible divergence. As [22,50] suggest, such a hybrid approach can be understood as 'cross-vergence'. In their argument, both convergence and divergence occur simultaneously, and as a result of interactions between the socio-cultural aspects, global convergence of business ideology, and divergence at local level, a complex hybrid system emerges. Therefore, in order to understand the extent of possible 'cross-vergence' of CSR-HRM practices, it is imperative to understand the relationship between socio-cultural norms, institutional factors, and CSR-HRM practices [51, 52]. NBS is used as an analytical framework throughout this chapter because it sees HRM as a collective outcome of institutional settings, such as labor market structures, training and education mechanisms, and unions $[23,53]$, which are influenced by societal and cultural norms.

\subsection{National business system and analytical framework}

Although NBS follows institutional theory's doctrine, it does not agree with the latter's notions of global diffusion of practices through isomorphic pressures. Instead it focuses on institutional pressures at a national level and the effect on organizations [26, 54, 55]. NBS emphasizes on a 'dominant' pattern of ownership systems, interfirm relations, and employment relations in a given country, which depend upon the existing institutional frameworks (political, financial, education and labor, and cultural systems), and this leads to the emergence of distinctive business systems [18, 21-23]. The fundamentals of NBS lie in historic, societal, and cultural norms [56], which are understood as 'accepted' conventions and regulations that have emerged from cultural values, both formally and informally [57]. Institutions established based upon this notion 
of social norms, therefore, can be understood as cognitive, normative, and behavioral systems of a society [16], which set the formal and informal 'rules of the game in a society' ([58], p. 3) that influence 'forms, outcomes, and dynamics of economic organisations' ([53], p. 3) through constraining or enabling certain patterns of behavior. Therefore, the outcome of such a framework is ideal business systems specific to a society, sector, or nation. An organization is likely to act within the rules and accept certain aspects of a society's norms, differentiating them from firms with different social backgrounds $[18,23,56,58,59]$. This theoretical approach of NBS provides a framework that can capture the complexities of institutional relations with HRMs in two different contexts with very different societal-cultural backgrounds and the extent of their convergence/ divergence. In the context of international business, social and cultural norms differ from nation to nation and are a particularly important factor due to the nature of CSR. Based on the logic of NBS, both formal and informal institutions allow certain types of HRM systems to function better and more efficiently in an economy than in others, because of their distinctive societal norms and institutional settings. This is further supported by Ignjatovic and Sveltic [60], who showed that certain HRM practices appear appropriate in one culture but less so in another. Aycan [51] also shows a moderating effect of cultural, institutional, and structural factors on HRM practices among countries. However, societal and cultural norms change and evolve under pressure from external influences $[61,62]$. Such external pressures also affect institutional frameworks, which can in turn influence existing societal and cultural norms [53]. Thus, the introduction of CSR can be regarded as external influence brought about by increasing global stakeholders' demand, which may create change in both institutional settings and societal and cultural norms. As argued in the previous section, HRM practices require systematic communication, training, and education with integrated CSR objectives and diversity management in order to be regarded as socially responsible HRM. NBS argues that there are two institutions in regard to HRM: (a) work organizations or professional associations and (b) training and education. While the role of the former has shifted to serve as a hub for systematic communication along with organizationallevel surveys or questionnaires, the latter remains another HRM-related institution. However, equal opportunities and/or diversity management were not considered institutional requirements prior to CSR. This is a consequence of changes in societal norms, brought about by globalization and rapid societal changes. Hence, by integrating CSR-HRM as previously identified and the logic of NBS, a new framework can be created (Figure 1), synthesized as the core analytical framework for this study.

Drawing on Jamali and Neville [22], the framework incorporates Whitley's [18] concept of NBS with Cooke and He's [7] concept of the CSR-HRM relationship to compile an institutional framework for CSR-HRM research. It positions organizations as the central unit of analysis and allows researchers to understand complex interactions of institutional pressures at any level and in any context. The framework captures an overview of a CSR-incorporated HRM with the understanding of the complex nature of institutional influence on national HRM practice; it allows comparison of two different contexts (the UK and Japan) and their CSRHRM practices at a national level within the same framework. There are five institutional settings related to HRM: state, cultural system, work organization, education and training, and diversity. They can be influenced by social and cultural norms and vice versa. Through the interaction between the norms and institutions, a distinctive organizational shape emerges. 


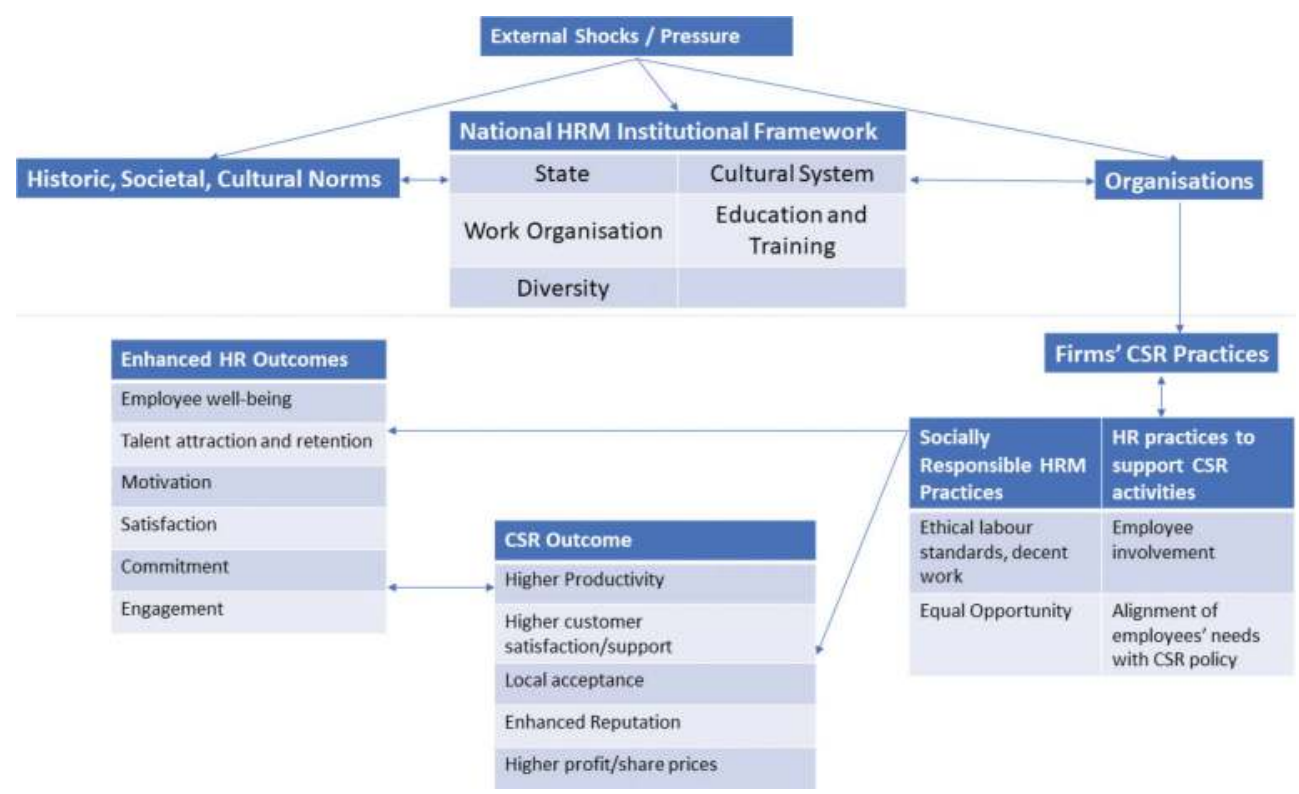

Figure 1. NBS-CSR-HRM analytical framework.

As argued earlier, three institutions are particularly important: work organizations (systematic communication), education and training, and diversity. These are highly interrelated with socially responsible HRM practices and have the capability of influencing firms' both CSR and HR outcomes. Thus, it is a key to understanding the complex interactions between the institutional settings and norms in order to achieve this chapter's objective: exploring the extent of convergence or divergence in CSR-HRM practices of the two very different contexts and the institutional role in ongoing convergence/divergence. As Carney et al. [63] argue, the reality of HRM practice is transitioning dynamically, due to rapid changes in the global business environment. While the transition certainly includes the wide adoption of CSR at a global level, understanding the transition and extent of convergence/divergence and institutional pressure can contribute to ongoing debates in CSR-HRM discourse [21, 22, 64, 65].

\subsection{Social-cultural norms and NBS of the UK and Japan}

As previous studies have revealed Britain and Japan exhibit two distinctive business system models (compartmentalized business system vs. highly coordinated business system), because of their distinctive social norms (individualism vs. collectivism), contrasts in the nature of their economic strength (UK service sector, Japan manufacturing sector), and contrasting institutional frameworks (specialist vs. generalist education/training, capital financial market vs. credit-based financial market, external labor market vs. internal labor, laid-back state vs. active state). 
The British and Japanese also have their own distinctive social characteristics, and their previous corporate organizational development and behaviors reflect these. Social norms in the UK can be defined as individualist, while the Japanese are regarded as more collectivist $[66,67]$. Under individualism, an individual's ideals and goals take prominence over the ideals of a group, whereas under collectivism there is a strong sense of the group, and individuals' ideals are placed below the group's interest. Therefore, with the UK public's strong feelings about privacy, individuals' freedoms, and rights, it can be argued that they reflect ideas of individualism, while the Japanese exhibit risk-averse behavior, strong feelings about community, and regard companies they work for as part of their social identity and thus can be regarded as collectivist [66]. Such elements are also well reflected in their institutional settings, such as high mobility of the external labor market, specialized education/training, free flow of ownership through the capital market and lack of intervention from the British government, and long-term employment including the generalist approach of education and training, internal labor market, coordinated development through credit-based financial market, and coordinated movement by the Japanese government [23].

As a result, the UK's corporate organizations tend to focus on short-term goals that could bring imminent benefits to shareholders, and employees lack loyalty to their organizations as it is relatively simply to switch jobs, which is further encouraged by specialist education and training. Thus it is not uncommon to see employees changing their jobs in pursuit of promotion or a better offer. In addition, employees are free to join unions that can protect their own interests, the bargaining power of which is dependent upon the union's strength, and they may join multiple labor unions, even though they may contradict each other in some areas. Thus a high level of employer-employee relations, loyalty, or trust is not to be expected.

Japan, on the other hand, has shown a very different approach: the idea of collectivism has resulted in a strong sense of group, and therefore when an employee joins an organization, it is regarded as his/her social identity, like being part of a family. This indicates a strong level of loyalty from a group of employees, and due to generalist education/training, which sees practical training as an extension of formal education, firms offer firm-specific training, and this leads to immobility of the labor force within the internal labor market. Hence, it is very common to see an employee work for a single company for a very long period, which in a Western context is understood as 'lifetime employment' [18].

\section{Methodology}

As discussed, studies have shown that differences in HRM resulted from different business systems in European countries [48, 51,60]. This study is designed to see if the same logic also applies to East Asia and to what extent. Therefore, Japan and the UK are selected, largely due to the significant differences between the two nations in terms of the business system and societal-cultural context. 


\subsection{Sample selection and profile}

The main methodological approach this chapter takes is a multiple case study, using theoretical sampling in selecting cases. Under this method, cases are selected based on their representativeness, richness in data, and fitness for the theoretical purpose of the chapter [68, 69]. Six cases are selected to maximize the manageability of data, as suggested by [68, 70], based on various factors that include size based on their income levels listed in Global Fortune 500 in 2012, significance in the relevant national economy, traditional value in their business system, CSR significance, and ownership structure. They each carry certain distinctive features of each business system and 'social legitimacy'. Thus, it can be argued that they are suitably representative of the two nations (Table $\mathbf{1}$ ).

\subsection{Data collection}

\subsubsection{Data collection}

Data for this study was collected through the three steps:

- Qualitative methods were widely applied through data collection. Direct observations and semi-structured interviews with experts, senior managers at each company, and employees were employed.

- Publicly available documents, data, and company reports (such as Nikkei Weekly newspapers, organizations' Annual Reports, Sustainability Reports, the Economics, etc.) are used for archival research purpose.

- Corroboration with third-party neutrals on collected data was also conducted to ensure validity. The third party was composed of experts in CSR management of both UK and Japan. In this case, the interviews lasted for over $3 \mathrm{~h}$ in an open dialog setting with questions designed to confirm findings from the collected datasets.

During the preliminary phase, background information collection and archival research were conducted to gather data on Japanese and British historical, cultural, and social contexts. Furthermore, acquisition and analysis of data regarding the cases' existing HRM policies and practices were also integrated into the interview process. Interviews with senior managers and fellow researchers with expertise in that nation's business system were carried out, and information was gathered through observation, which facilitated the understanding of differences in societal and cultural norms as well as CSR-HRM. Interviews were taken in both formal and informal settings between 2 and $3 \mathrm{~h}$, which were recorded. They were conducted in semi-structured formats, allowing the freedom to elaborate on interpretations while maintaining the broad themes of the interview (three key institutional elements in CSR-HRM), to maximize data that can be collected.

- Systematic communication: NBS emphasizes the institutional function of work organizations (such as trade unions) and their role in organizations' HRM choices [23, 71]. In a nation where trade unions are strong, they are more likely to be involved in a company's 


\begin{tabular}{|c|c|c|c|c|c|c|}
\hline \multirow[b]{2}{*}{ Parameters } & \multicolumn{3}{|c|}{ UK } & \multicolumn{3}{|c|}{ Japan } \\
\hline & Company A & Company B & Company C & Company 1 & Company 2 & Company 3 \\
\hline Revenue (\$mil) & Top range & Mid-range & Mid-range & Top range & Mid-range & Low range \\
\hline $\begin{array}{l}\text { Number of } \\
\text { employees }\end{array}$ & $80,000+$ & $100,000+$ & $100,000+$ & $60,000+$ & $100,000+$ & $20,000+$ \\
\hline Type & Publicly listed & Publicly listed & $\begin{array}{l}\text { Privately } \\
\text { owned }\end{array}$ & Publicly listed & Publicly listed & $\begin{array}{c}\text { Privately } \\
\text { owned }\end{array}$ \\
\hline $\begin{array}{l}\text { Age (year } \\
\text { established) }\end{array}$ & 1982 & 1727 & $\begin{array}{l}1984 \text { (privately } \\
\text { owned since } \\
2006 \text { ) }\end{array}$ & 1954 & 1899 & 1899 \\
\hline Note & $\begin{array}{l}\text { One of the } \\
\text { largest } \\
\text { corporations in } \\
\text { the UK }\end{array}$ & $\begin{array}{l}\text { One of the } \\
\text { largest financial } \\
\text { organisations } \\
\text { globally that } \\
\text { has been } \\
\text { owned by UK } \\
\text { holders }\end{array}$ & $\begin{array}{l}\text { The largest } \\
\text { privately } \\
\text { owned } \\
\text { enterprise in } \\
\text { the UK; turned } \\
\text { private through } \\
\text { M\&A, showing } \\
\text { the distinctive } \\
\text { business } \\
\text { culture of the } \\
\text { UK }\end{array}$ & $\begin{array}{l}\text { One of the } \\
\text { oldest keiretsu } \\
\text { companies in } \\
\text { Japan; formerly } \\
\text { played the } \\
\text { central role in } \\
\text { the keiretsu } \\
\text { network }\end{array}$ & $\begin{array}{l}\text { One of the } \\
\text { oldest } \\
\text { electronic } \\
\text { companies in } \\
\text { Japan; the only } \\
\text { original } \\
\text { electronic } \\
\text { company that } \\
\text { operates in } \\
\text { both general } \\
\text { and household } \\
\text { markets }\end{array}$ & $\begin{array}{l}\text { One of the } \\
\text { oldest and } \\
\text { largest } \\
\text { privately } \\
\text { owned } \\
\text { companies in } \\
\text { Japan; M\&A } \\
\text { never occurred, } \\
\text { unlike in the } \\
\text { UK }\end{array}$ \\
\hline
\end{tabular}

Table 1. Case profile.

employee management and can establish strong employer-employee relationships; however, if trade unions are decentralized, the reverse may occur. However, with the introduction of CSR, which requires responding to stakeholders' expectations, firms have been able to maintain relations with employees, with assistance from work organizations. Therefore, for the purposes of this study, 'work organization' is reinterpreted as 'systematic communication', understanding the nature of employer-employee relationships, and how a firm's systematic communication is structured.

- Education and training: training and education is one of the key institutional settings that influence a nation's HRM practice, as presented and supported by NBS [18]. As mentioned, the extent of the incorporation of CSR into the existing training system deters the organizations' CSR outcomes. Like a Japanese business system with heavy reliance on internal labor market, trainings are based on the firm or are industry specific. This is to enhance competitive advantage of both organizations and employees [72]. On the other hand, in a business system based on an individualistic nature like the UK, role-specific and outcome-oriented 
trainings are provided $[48,51]$. Therefore, understanding the extent of CSR integration in existing education and training, generalist, or specialist approaches can be a key determinant in identifying the nature of HRM in the two contexts.

- Diversity: in this study, diversity includes gender, ethnicity, and nationality. This variable is selected to help identify the nature of the labor market system. As argued, diversity is becoming increasingly important in the modern era, as a result of increased awareness in human rights. Previously, due to the collectivist nature of the Japanese society, it was understood as a society with a high level of 'stickiness' [73] with a low mobility of employees and 'lifetime employment' created by the internal labor market system. Therefore, diversification and individualization of employees were discouraged [74], creating an unfriendly environment for foreign employees. However, as the global society is becoming multicultural as a result of globalization, diversity is also understood as offering equal opportunities to employees and being socially responsible, which makes it worth the investigation. Therefore, this is another essential step to understand a business system's convergence/divergence in terms of CSR-HRM.

The semi-structured interviews were designed based on these three themes, identified through the literature review and preliminary research. The interviews were not conducted in a fixed format, but rather varied and flexible, depending on the responses. This was to allow the researcher to obtain unexpected knowledge and expand the data in regard to employee management. Every interview was recorded by a voice recorder, with the participants' permission, and conducted in English. In the last phase, a data validity check was performed that is the transcribed data were double checked with the participants and interpreter. Further, through the introduction of the Japanese Chamber of Commerce in the UK, the author was able to gain access to an organization that advises Japanese companies that wish to operate in the UK on their CSR management and policies. The organization was also interviewed in an open dialog setting to check the validity of data and balance data that might be biased.

\section{Outcomes}

With globalization and increased information availability resulting from rapid technological advancement, the boundaries and roles of organizations have become much broader [75]. As a result, various international organizations were introduced, exerting regulatory forces and causing changes in institutional settings [63]. Thus, it has been argued that institutions are increasingly becoming more homogenous because there is now pressure from levels above the national level, through coercive, mimetic, and normative processes [10, 11], which result in organizational behaviors becoming more homogenous than ever [10-12]. However, the findings show rather mixed results. In this section, those results will be presented, which will then be followed by a discussion of the outcomes.

\subsection{Systematic communication}

Based on all six cases' results relating to their means of communicating with employees, these can be broadly categorized into two modes: general survey/questionnaire and formal meetings between employees and their superiors, undertaken annually or quarterly depending on 
the organization. In contrast to the former, formal meetings between the employees and their supervisors take place on a regular basis. Employees are composed of both employees and union representatives, and the meetings are conducted with either board members or seniorlevel officers of the same division.

In the case of Company A, the annual survey is taken at the global level with a $90 \%$ participation rate. The questions are designed to attain data related to employee expectation and further to monitor their performance. Therefore the analysis procedure involves two different standards: one measures the extent of employees' actions within the company's CSR framework and the other seeks for the employees' view on the company's CSR policies. Company B's systematic communication is also largely based on their two forms of surveys, both of which are conducted regularly. A total of $81 \%$ of the total employees participate in their annual survey throughout the organization and $15 \%$ of the population in their quarterly based smaller-scale surveys. Both surveys are to gather information on employees' views on the organization's actions, which include CSR. However, in contrast to the previous two cases, Company $\mathrm{C}$ does not perform surveys across the group. Instead they allow autonomy to each of their businesses within the group to perform surveys of their own. Each of them measures employees' views on an organization's actions as well as their satisfaction and is conducted annually with high participation rates (96\% in the UK). The outcomes of surveys from each business unit are analyzed and reported to the headquarters, which can provide more manageable data and outcomes than global-scale surveys.

The Japanese cases (Company 1, 2, and 3) also show a similar approach, with one significant difference. As noted, Japanese unions are structured as enterprise unions, which appear to be serving a significant role in systematic communication in Japanese organizations in every aspect, including CSR actions, for example, the staff union of Company 1. Both Companies 1 and 2 show their staff union conducting annual surveys. Company 2's senior manager responded that 'we do have [a] union survey every year with about 200 questions'. On the other hand, Company 3 shows a rather unique paternal approach in comparison to the other cases. They do not conduct questionnaire-type surveys, but communication is performed through, for four times a year, supervisor-subordinate interviews. Moreover, interviews are conducted throughout the group at the beginning of every year to understand employees' job satisfaction as well as their issues on working conditions/environment. Despite such a paternal approach, when Japanese employees were prompted with a question regarding their freedom to express, they showed reluctance in expressing negative opinions of their own company, whether it is a survey or they were interviews. This is a direct contradiction to British cases, which responded 'we feel free to say anything', when a Company 2 employee responded '[I] feel scared to ask [...] supervisors'.

Aside from the surveys on a regular basis, evidence suggests that organizations are also using formal meetings between employees and senior managers as another form of systematic communication. They are undertaken on a regular basis with board members and CEOs at present, which are performed in smaller and casual forms as well as in formal settings whether inside or outside the office. This is a rather unusual case for a highly individualistic society like the UK. However, all three cases from the UK show the same movement. For example, Company A has introduced round-table sessions for employees to express their opinions and concerns to their senior managers or the CEO directly. The employees are employee representatives, who are elected through the peer-voting system and do not need any particular 
qualifications, positions, or length of service. These sessions are conducted at least once a year regardless of the nations their offices are located in, and the employee representatives have open discourses with the executives on the organization's policies, practices, and any other concerns that colleagues may have. Therefore it allows both employees and senior managers to have a better understanding of each other and their expectations. Company B has a similar approach. They hold various forms of conferences for employees at different levels. Each division within the organization holds both divisional conferences and smaller fora that occur more frequently. The conferences are held at least once a year along with other forms of quarterly meetings with 400-500 people. Furthermore, as well as in the case of Company A, Company B's employees set up employee representative bodies across Europe to share and express their views on an organization's practices and policies. This activity also exists in Company $\mathrm{C}$ with cross-national employee representative dialog sessions every year.

As with the case of annual surveys or interviews, evidence shows that formal meetings between employees and the senior managers are also organized through enterprise unions. Within the staff union of Company 1, there are unions representing branches, two of whom meet and discuss their concerns regarding the organization frequently (20-30 times a month) regardless of their divisions at various levels. The staff union raises the outcome of the meetings at the biannual formal meetings with the management, including the president of the organization. This is similar to Company 2's systematic communication method, which engages in regular gatherings at every level of the organization. There are gatherings at both group and labor-management levels three times per year and unit-level meetings on a more frequent basis. In case of Company 3, there are council meetings between senior managers and the enterprise union, which are arranged once or twice a year, and they also collect employee feedback on a personal basis via interviews between superiors and subordinates (as mentioned earlier) four times a year.

\subsection{Education and training}

Using Whitley's [23] terminology, the UK's education and training can be understood as 'specialist': training is role specific and performance oriented [18, 23, 48, 51]. On the other hand, due to firm-specific or industry-specific training with job rotation, Japanese training is considered 'generalist'. Such traditional institutional settings appear to be true in all six cases, with some indication of possible convergence.

\subsubsection{Specialist approach (the UK)}

The specialist approach of the UK largely remains unchanged, as shown from Company A's senior manager's response when prompted with a question regarding the organization's support to own employees for trainings that are unrelated to their roles: 'no, no, it's got to be relevant to our industries, it's got to be relevant to the jobs they are doing'. However, unlike the previous case, Company B shows a new adoption, job rotation at limited extent, into their existing training scheme. The new approach resembles a smaller scale of the Japanese's traditional ringi system but is limited to branch-branch/HQ-subsidiary instead of their roles. Regardless, it indicates that there is a certain level of transition within the training system of the UK. All three cases show that organizations provide a certain extent of freedom to 
employees to participate in trainings that they see appropriate, and yet if they are irrelevant to their roles, they need to be conducted outside office hours and at their own expense. Trainings provided by organizations are generally industry or role oriented, and it is up to the employees to select the most suitable trainings for their career advancement, as shown by a CSR manager of Company A who reacted thus:

We provide training from MD2 level to degree level, but it is not in some specific area. So it would be down to individuals [...] when it goes up into higher studies of education, it is down to employees to apply to do what they see fit. Then it's approved all by senior management.

Moreover, the evidence suggests that trainings are provided in either classroom settings or online formats, but this does not include CSR-specific training. In general employees are given regular mandatory training relevant to the role they are holding, and the concept of responsible business in relation to the role is embedded in their trainings. For instance, if one is working in HR, he/she will be trained in diversity, employee well-being, and so on. Such an approach can be understood as job-specific CSR training, and this is well reflected from a senior manager of the CSR division of Company B's comments:

[I]s it important to us that everybody knows the definition of sustainability? No. Is it important to us that people are thinking long-term, making [the] right decisions, putting the customers higher than what they do? Yes.

[T] o us, it's not really [about] people knowing what sustainability is or what sustainability stands for. It's more about how can we influence the organisation and make sure that kind of responsible behaviour and [those] actions are taking place.

The responses are clear about their belief in having CSR-specific training, which is not necessary to be performed in formal, classroom settings. However, it is crucial to have the concept embedded in the jobs they carry out. Therefore, CSR is promoted through deep integration into their everyday businesses, which would lead their employees to perform their roles in socially responsible ways without deliberate intentions. This is further assisted through their mandatory trainings on critical issues, like ethics, business conduct, and integrity, with support of information distributed online. They are largely organized as on-the-job training, while they are also encouraged to participate in various corporate citizenship activities to be more aware of their communities and potential issues.

\subsubsection{Generalist approach (Japan)}

While the UK appears to have integrated CSR training into existing job-/role-specific training, the Japanese cases maintain their traditional approach of 'job rotation'. In terms of distinctive features of their training mechanisms, each responded with 'job rotation', a traditional Japanese policy known as the ringi system, and regarded as a generalist approach, in contrast to the UK's specialist approach, as Nikkei Weekly [76] describes it. Figure 2 is one of the case companies' training structures. As shown, employees can choose appropriate rolespecific trainings aside from the management training; however, they only become available when they are at senior management positions. Due to their characteristics, it is difficult for Japanese organizations to integrate or embed CSR into their job-training systems like the UK cases have shown. Thus, employees receive CSR-specific training separately, which is mandatory for all employees upon their enrolment followed by assessments, as all cases 


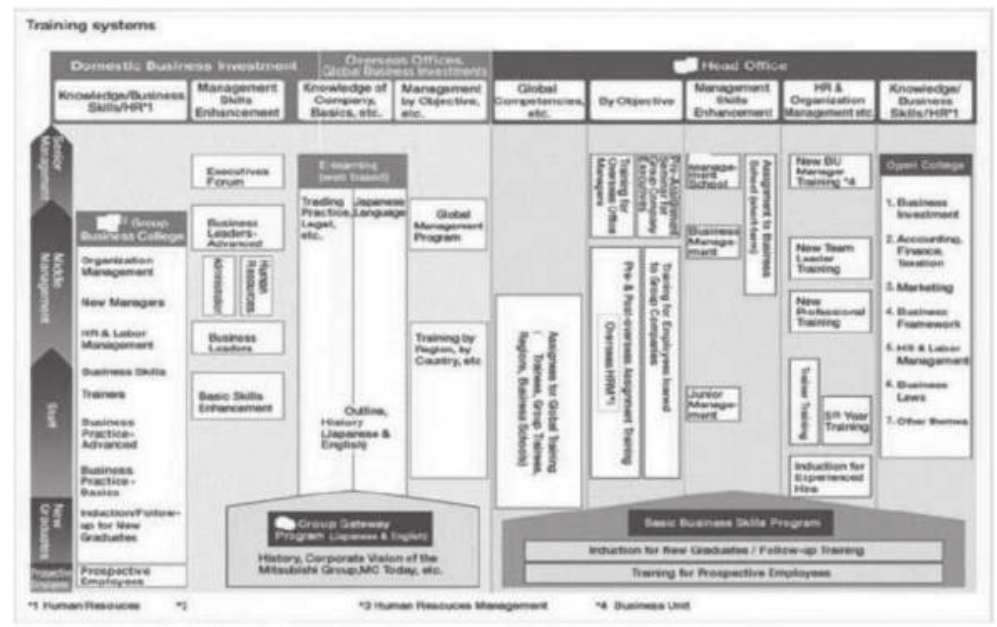

Figure 2. Japanese Firm's training mechanism [55].

show. Companies 1 and 3 perform this through online (e-learning) and Company 2 performs it through direct delivery of lectures on CSR in a classroom setting. In addition, handbooks, magazines, and ore pamphlets are provided to further enhance employee awareness in CSR issues. Aside from the on-the-job training and the traditional Japanese training system, archival research shows there is another new form of training in Japanese organizations, off-the-job training [77]. It is gaining ground due to increasing international competition and institutional pressure resulting from globalization. Though they are yet limited, their intention is to provide both specialized skill sets and additional knowledge to employees based in Japan Institute for Labour Policy and Training's (JILPT) description. However, evidence of this was not in tandem with the cases. Furthermore due to a decrease of birth rate and the aging society as well as increased demand for non-regular or atypical employees, the traditional lifetime employees are in decline (see [78-80]). This result of recent studies is further supported by [77], which shows changes in employers' preference from traditional regular employees to employees with specialized skill sets who can bring immediate results for the company. This may be an indication of a shift in Japanese organizations' approach from traditional lifetime employees and generalist frameworks, which can be seen from the following response of an employee who was in his third job:

It used to be considered to be taboo to switch the companies you work for, but now it is not so much, especially with foreign companies.

Despite the statement as well as the outcome of archival research, some cases show a rather conflicted result. In case of Company 1, the average time at the organization of their employees was 18.9 years and 15.4 years in case of Company 3. Trainings also focused on raising regular employees (sogo shoku) rather than non-regular employees (ippan shoku) or employees with specialized skill sets. Therefore, the result implies that despite the ongoing trend in Japanese labor structure overall, certain aspects in Japanese training and education still remain unchanged. 


\subsection{Diversity}

As discussed previously, diversity is considered to be an important factor to consider for business with the introduction of corporate sustainability. Increased awareness of equal opportunities and human rights means that society demands greater responsibility for firms to promote diversity at the workplace. However, in probing organizations' HRM practices in relation to diversity, respondents struggled to give direct reasons but rather presented their organizations' responses to diversity issues.

\subsubsection{Diversity in gender}

OECD shows a balanced gender diversity ratio in the UK; however, all cases show a decrease in gender ratio as positions go higher. In Company A, the female ratio at each level of positions is $20 \%$ (top management), $22 \%$ (senior management), and $24 \%$ (middle-level management) and in Company B, 33\% (managers), 27\% (senior managers), and 19\% (executive). Given the high level of women's labor participation rate in the UK, this is rather a surprising outcome. However, none of the case organizations could present a convincing explanation other than calmly responding to show their awareness of the issue and their effort in improving the situation. A CSR manager of Company B, however, attempted to address this by, 'I think those women's priorit[ies] change and their priority is their family and having that time in their life to pursue looking after their family as oppose[d] to pursuing getting on to the next scale or level of management'. And 'I am a woman, but I do feel a lot of women prioritise [...] family over career progression'. These two responses may indicate a potential change in women's priorities as their career progresses; however, they are not adequate to generalize as a possible phenomenon. The gender diversity issue is even more severe in case of Japan. As mentioned in the previous section, there are two types of employees, ippan shoku (non-regular employees) and sogo shoku (regular employees). In Japan it is a generally accepted norm that regular employees are largely composed of males, and females tend to be given the non-regular employees status. An employee from Company 2 stated that 'I joined this company six years ago, and at that time [there were] seventy new workers, 45 male and 25 female, and amongst the 25 female only three made [it] to sogo shoku'. Her response shows the existing difficulties in achieving higher levels in careers for women, which discourage them to pursue a career as a goal. This is well reflected from an interview with an expert participant, during which it was discovered that it is actually a social issue that has been lasting long in Japan rather than an organizational problem. Based on the [81], in Japanese society, female labor participation rate is only at $43 \%$ of the total female population. Such lack of involvement by women is also shown from the cases: female ratio for each case is only $25 \%$ (Company 1), $18 \%$ (Company 2), and a little less than 15\% (Company 3). To explain this phenomenon, the expert argued that 'Japanese women do not have the concept of working for their career, but their main objective is to find a good husband and settle down', which shows the gender diversity issue persists in Japan and further indicates that the traditional value of male dominance in the society also persists.

\subsubsection{Ethnicity and nationality diversity}

A similar issue also exists regarding foreign labor in Japan. Due to their collectivist nature, in contrast to the UK's individualistic multicultural society, foreign labor forces always have to 
battle through the 'glass ceiling'. As mentioned, the Japanese high level of collectivism creates an environment which unwelcomes outsiders/foreigners as a part of their society and community. An existing language barrier, as well as high-context culture, makes it even more difficult for outsiders to be accepted by such a close-knit community. For example, the meetings with managers of an organization's foreign branches and headquarters are generally held in Japanese [67]. When prompted, all the company representatives responded 'we are trying to improve the situation'. This is also further supported by the [77] survey, which presents that $67.2 \%$ of total employers do not prefer to hire foreign employees, despite the increasing number of foreign labor in Japan. Furthermore, the remaining 33.8\% of employers claimed that an important precondition to hire foreign employees is their fluency in Japanese rather than their skilled sets. This is further supported by the following comment from a CSR team leader of Company 2:

\section{[...] [t]here is a barrier, communication barrier. Our top management know that it is very important to know (learn) how to speak English, and everybody outside speaks English too. They are realising the situation. Well [...] maybe [in] 2-3 years' time [it will get better].}

\subsubsection{Promoting diversity}

In contrast to the findings that show maintaining traditional values in both countries, there are also some indications for changes. In Japan, both government and firms are showing efforts in promoting foreign employees and the use of external labor market. With the government establishing a national objective to increase the amount of foreign labor intake, Company 1 responded with introducing the use of common office language (English and Japanese) and a separate training system more appropriate for foreign workers. All Japanese cases are showing various benefits as well as working hours for female employees to promote gender diversity. However, the UK cases show a slight different approach compared to their Japanese counterparts in promoting gender diversity, such as introducing new policies or workshops. Company A has introduced a new policy, which enforces the organization to maintain a 50:50 gender ratio at all levels. Therefore, when it falls below the ratio, managers are encouraged to hire more females. All three cases also show workshops in place, of which the goals are to assist women in career advancement and to provide support to fellow female employees through mentor-mentee relations.

\section{Discussion and conclusion}

Through the literature review, it has become evident that national culture is an important factor that 'directly or indirectly influences work-related cultures' ([82], p. 2425). Much of other literature also identified that differences in the NBS systems and HRM result from societal, cultural, and institutional setting differences (see [18, 19, 23, 47, 48, 53, 54, 59, 66, 73, 74, 83-86]). The results of this study also strongly support such logic of the NBS. Adopting the CSR language throughout all cases is a possible indication of convergence. Furthermore, as responses regarding a reason for implementing CSR by Japanese cases ('because our partner companies want us to' and 'because everyone is doing it') show, it is evident that coercive and mimetic isomorphic pressures have encouraged the firms to adopt CSR into their practice to some extent. However, the findings also showed possible divergence at a microaspect. 
Organizations and institutional pressures have complex relations; not only do they require an understanding of organizations but they also require an understanding of institutional pressures at both national and global levels. The framework in Figure 1 was devised to reduce such complexities and enable scholars to understand and discuss the extent of convergence/divergence of the two nations' HRM practices. The framework identified three key institutional factors in forming national HRM systems based on an NBS perspective: systematic communication (work organizations), education and training, and diversity. Their influence on HR practices that supports the organization's CSR activities and socially responsible HRM practices has direct relation to the organization's CSR outcome. As argued, work organizations should be regarded as an important institutional factor that can determine the extent of an organization's systematic communication. It promotes employee participation as well as aligns their needs with the organization's CSR policy. The Japanese cases showed the significance of enterprise unions in promoting employee involvement and their communication with their organizations. The UK that has been known for highly decentralized work organizations [23]; however, this shows a certain level of transition from their typical individualist approach. Their work organizations still remain weak, but it appears that a new form is also introduced. Round-table meetings between employee representatives and senior managements on a regular basis resemble the enterprise union system of Japan and how they function. This shows that there is a possible convergence in the work organization institutional setting, or at least it is safe to say the institution does not hinder the possible convergence of CSR-HRM of the two nations. In contrast, the institutional setting of training and education appears to be maintaining their traditional forms. As argued, training and education assist socially responsible HRM practices to enhance ethical labor standards and their CSR perceptions. And in the case of the UK, its traditional approach (specialist based) remains, while Japan maintains generalist-based training systems. The integration of CSR concepts into existing British job-specific training is in contrast to the Japanese, whose training takes a generalist approach. In addition, Japanese cases show that their training is symbolic and informative, rather than aiming to embed CSR concepts into employees' roles and views. However, unlike the other two institutional settings, diversity appears to be in chaos, especially in Japan. Thanks to its multicultural society and high level of awareness in feminism, the UK takes a relatively balanced approach through providing various rights, benefits, and workshops. However, Japanese cases show that male-dominant social characteristics and barriers caused by a high level of collectivism still largely remain. Although findings indicate that various actions and policies have been taken to promote diversity at the organizational level, there is no clear evidence to suggest that they have positively impacted existing issues on diversity. It can be argued that at least there is a certain level of convergence with regard to the policies at the organizational level, but without clear evidence on their practical implications, convergence in diversity institutional settings is yet to be confirmed and generalizable. The fact that the other two institutional settings remain the same shows that they have not yet converged, despite the wide use of the language of CSR, along with other signals suggesting convergence at an 'explicit' level.

As shown in Figure 1 and the evidence, multiple institutional levels exert influence over their CSR-HRM systems in complex ways. Global institutional pressure has led both nations to incorporate CSR into their existing HRM models. National institutional pressure leads organizations to operate CSR-HRM that fits their society, as argued by the NBS. Thus, as a result of differences in both their culture and business systems, divergence at a micro-level or rather at an 'implicit' level also occurs. The UK's integration of CSR training with existing 
role-specific training schemes based on a specialist approach, and providing CSR-specific training along with assessments, reflecting its generalist approach, is a clear sign of salience of the two nations' institutional pressures in comparison with the global institutional pressure for convergence. This is also supported by remaining enterprise unions, gender diversity issues, along with glass ceiling in Japan.

In sum, CSR-HRM of the two nations shows a certain level of convergence at an explicit level resulted by coercive and mimetic pressures from global institutions, but there is also evidence that suggests the predominance of national institutional pressures causing divergence in CSR-HRM at an implicit level. Therefore, it can be argued that through the interactions between the institutional pressures from both national and global levels, a rather hybrid form of CSR-HRM is in place [22]. With the assistance of the developed framework (Figure 1), it was possible to identify and explore the complexities of institutional interaction to promote convergence and divergence of CSR-HRM in this research. The result pointed that UK's change in work organization settings, the adoption of CSR, and attempts in improving diversity-related policies and actions of Japanese organizations indicate possible convergence

\begin{tabular}{|c|c|}
\hline Outcome & Institutional Change \\
\hline \multirow{3}{*}{ Convergence } & $\begin{array}{c}\text { Common use of the CSR language shows global institutional pressure's } \\
\text { coercive and mimetic isomorphism }\end{array}$ \\
\hline & $\begin{array}{l}\text { Increased use of work organisations is similar to Japanese enterprise } \\
\text { unions for effective systematic communication (UK) }\end{array}$ \\
\hline & $\begin{array}{l}\text { Introduction of various forms of policies and practices to promote } \\
\text { diversity (Japan) }\end{array}$ \\
\hline \multirow{3}{*}{ Divergence } & $\begin{array}{l}\text { National societal-cultural values and norms are deeply rooted in their } \\
\text { operations }\end{array}$ \\
\hline & $\begin{array}{l}\text { UK's specialist approach and Japanese generalist approach in education } \\
\text { and training remain strong }\end{array}$ \\
\hline & $\begin{array}{c}\text { Japan largely relies on enterprise unions in communicating with } \\
\text { employees; 'glass ceiling' and lack of female labour participation still } \\
\text { remain in Japan, despite their efforts }\end{array}$ \\
\hline
\end{tabular}

Table 2. Convergence and divergence of British and Japanese CSR-HRM. 
resulting from global institutional pressures. However, at the same time, the remaining institutional settings, such as traditional approaches in training education, and diversity-related issues of Japan, also show that national institutional pressures still predominate in certain areas causing divergence (see Table 2). The outcome of this research is in an agreement with $[21,22]$, who argued that convergence occurs due to the increasing global institutional pressure, while differences in NBS also drive divergences between nations. Lastly, as the findings suggest, the difference in local institutional framework will persist as long as the differences in cultural and societal norms exist, which will place national institutional pressures in a more predominant position than the increasing global institutional pressure due to globalization. Such a finding, therefore, shows and supports the 'cross-vergence' argument of [22, 50]. These norms are deeply rooted in organizations and their behaviors as well as their institutions, and they will continue to influence CSR-HRM in different contexts.

CSR is not yet well standardized, and therefore much effort has been paid to present frameworks or guidelines to promote the convergence of CSR. Wang and Juslin [20] argued that CSR is a concept derived from the West, and as its understanding is not well established in the East, an Eastern form of CSR may be necessary. However, this chapter argues that it is not necessary: integration of convergence and divergence may suit organizations in a more competitive way. Thus, it is important to understand the complexity of institutional relations with organizations' CSR-HRM, which includes global HRM institutional pressure, national societal-cultural values and norms, national HRM institutional pressure, and responses from organizations. When the complexity of these relationships is understood, more systematic and stronger forms of CSR can be realized.

\section{Acknowledgements}

I thank all those members of the organizations who participated in the interviews and contributed to the study. I also thank Professor Jeffrey Henderson and Dr. Gaston Fornes, who had helped and supervised the overall progress of the research, and I am really grateful for their supports through the journey.

\section{Conflict of interest}

No conflict of interest.

\section{Author details}

William Il-kuk Kang

Address all correspondence to: williamil-kuk.kang@manchester.ac.uk

Faculty of Humanities, Alliance Manchester Business School, University of Manchester, UK 


\section{References}

[1] Bauman C, Skitka L. Corporate social responsibility as a source of employee satisfaction. Research in Organizational Behavior. 2012;32:63-86. DOI: 10.1016/j.riob.2012.11.002

[2] Phillips R. Stakeholder Theory and Organizational Ethics. San Francisco, California: Berrett-Koehler; 2003

[3] Guest D, Michie J, Conway N, Sheehan M. Human resource management and corporate performance in the UK. British Journal of Industrial Relations. 2003;41(2):291-314. DOI: $10.1111 / 1467-8543.00273$

[4] Mohtsham Saeed M, Arshad F. Corporate social responsibility as a source of competitive advantage: The mediating role of social capital and reputational capital. Journal of Database Marketing \& Customer Strategy Management. 2012;19(4):219-232. DOI: 10.1057/dbm.2012.19

[5] Rowley T, Berman S. A brand new brand of corporate social performance. Business \& Society. 2000;39(4):397-418. DOI: 10.1177/000765030003900404

[6] Rupp D, Ganapathi J, Aguilera R, Williams C. Employee reactions to corporate social responsibility: An organizational justice framework. Journal of Organizational Behavior. 2006;27(4):537-543. DOI: 10.1002/job.380

[7] Cooke F, He Q. Corporate social responsibility and HRM in China: A study of textile and apparel enterprises. Asia Pacific Business Review. 2010;16(3):355-376. DOI: $10.1080 / 13602380902965558$

[8] Morgeson F, Aguinis H, Waldman D, Siegel D. Extending corporate social responsibility research to the human resource management and organizational behavior domains: A look to the future. Personnel Psychology. 2013;66(4):805-824. DOI: 10.1111/peps.12055

[9] Hahn T, Pinkse J, Preuss L, Figge F. Tensions in corporate sustainability: Towards an integrative framework. Journal of Business Ethics. 2014;127(2):297-316. DOI: 10.1007/ s10551-014-2047-5

[10] DiMaggio P, Powell W. The iron cage revisited: Institutional isomorphism and collective rationality in organizational fields. American Sociological Review. 1983;48(2):147. DOI: $10.2307 / 2095101$

[11] DiMaggio P, Powell W. The New Institutionalism in Organizational Analysis. Chicago: University of Chicago Press; 1991

[12] Meyer JW. Reflections on institutional theories of organisations In: Greenwood R, Oliver C, Suddaby R, Sahlin-Andersson K. The SAGE Handbook of Organizational Institutionalism. London, England: SAGE Publications; 2008. pp. 790-812. DOI: 10.4135/9781849200387.n35

[13] Meyer J, Rowan B. Institutionalized organizations: Formal structure as myth and ceremony. American Journal of Sociology. 1977;83(2):340-363. DOI: 10.1086/226550 
[14] Meyer J, Boli J, Thomas G, Ramirez F. World society and the nation-state. American Journal of Sociology. 1997;103(1):144-181. DOI: 10.1086/231174

[15] Jepperson RL, Centre RS, Forum E. The Development and Application of Sociological Neoinstitutionalism, European University Institute, Robert Schuman Centre; San Domenico di Fiesole, Italy; 2001

[16] Scott WR. The adolescence of institutional theory. Administrative Science Quarterly. 1987;32(4):493-511. DOI: 10.2307/2392880

[17] Waddock S. Building a new institutional infrastructure for corporate responsibility. Academy of Management Perspectives. 2008;22(3):87-108. DOI: 10.5465/AMP.2008. 34587997

[18] Whitley PR. Business Systems in East Asia: Firms, Markets and Societies. CA: Sage Publications; 1992

[19] Hall PA, Soskice D. Varieties of Capitalism: The Institutional Foundations of Comparative Advantage. Oxford: OUP; 2001

[20] Wang L, Juslin H. The impact of Chinese culture on corporate social responsibility: The harmony approach. Journal of Business Ethics. 2009;88(3):433-451

[21] Matten D, Moon J. "implicit" and "explicit" CSR: A conceptual framework for a comparative understanding of corporate social responsibility. Academy of Management Review. 2008;33(2):404-424. DOI: 10.5465/amr.2008.31193458

[22] Jamali D, Neville B. Convergence versus divergence of CSR in developing countries: An embedded multi-layered institutional lens. Journal of Business Ethics. 2011;102(4):599-621. DOI: $10.1007 / \mathrm{s} 10551-011-0830-0$

[23] Whitley R. Divergent Capitalisms: The Social Structuring and Change of Business Systems. New York: Oxford University Press; 2000

[24] Hofstede GH. Culture's Consequences: Comparing Values, Behaviors, Institutions, and Organizations across Nations. California, USA: Sage Publications; 2001

[25] Lee SM, Choi IC. Revisiting Corporate Social Responsibility. Seoul, Korea: Samsung Economic Research Institute (SERI); 2002

[26] Tempel A, Walgenbach P. Global standardization of organizational forms and management practices? What new institutionalism and the business-systems approach can learn from each other. Journal of Management Studies. 2007;44(1):1-24. DOI: 10.1111/ j.1467-6486.2006.00644.x

[27] Carroll AB. A three-dimensional conceptual model of corporate performance. The Academy of Management Review. 1979;4(4):497-505. DOI: 10.2307/257850

[28] Margolis JD, Walsh JP. Misery loves companies: Rethinking social initiatives by business. Administrative Science Quarterly. 2003;48(2):268-305. DOI: 10.2307/3556659

[29] Garriga E, Melé D. Corporate social responsibility theories: Mapping the territory. Journal of Business Ethics. 2004;53(1/2):51-71. DOI: 10.1023/B:BUSI.0000039399.90587.34 
[30] Godfrey PC, Hatch NW. Researching corporate social responsibility: An agenda for the 21st century. Journal of Business Ethics. 2007;70(1):87-98. DOI: 10.1007/s10551-006-9080-y

[31] van Beurden P, Gössling T. The worth of values-A literature review on the relation between corporate social and financial performance. Journal of Business Ethics. 2008; 82(2):407. DOI: 10.1007/s10551-008-9894-x

[32] Crane A, Matten D, McWilliams A, Moon J, Siegel DS, editors. The Oxford Handbook of Corporate Social Responsibility. Oxford: OUP; 2008. DOI: 10.1093/oxfordhb/97801 99211593.001.0001

[33] Geva A. Three models of corporate social responsibility: Interrelationships between theory, research, and practice. Business and Society Review. 2008;113(1):1-41. DOI: 10.1111/j. 1467-8594.2008.00311.x

[34] Aguinis H, Glavas A. What we know and don't know about corporate social responsibility: A review and research agenda. Journal of Management. 2012;38(4):932-968. DOI: $10.1177 / 0149206311436079$

[35] Turban DB, Greening DW. Corporate social performance and organizational attractiveness to prospective employees. The Academy of Management Journal. 1997;40(3). DOI: 658-72. DOI: $10.2307 / 257057$

[36] Albinger HS, Freeman SJ. Corporate social performance and attractiveness as an employer to different job seeking populations. Journal of Business Ethics. 2000;28(3):243-253. DOI: 10.1023/a:1006289817941

[37] Brammer S, Williams G, Zinkin J. Religion and attitudes to corporate social responsibility in a large cross-country sample. Journal of Business Ethics. 2007;71(3):229-243. DOI: 10.1007/s10551-006-9136-z

[38] Sharma S, Sharma J, Devi A. Corporate social responsibility: The key role of human resources management. Business Intelligence Journal. 2009;2(1):205-213. DOI: 10.1.1.514. $7758 \&$ rep $=$ rep $1 \&$ type $=$ pdf

[39] Inyang B, Awa HO, Enuoh RO. CSR-HRM nexus: Defining the role engagement of the human resources professionals. International Journal of Business and Social Science. 2011;2(5 (Special issue)):118-126

[40] Jamali D, Dirani A. Synergies of CSR and diversity management: A converging agenda. In: Karatas-Özkan M, Nicolopoulou K, Özbilgin MF, editors. Corporate Social Responsibility and Human Resource Management. Cheltenham, UK: Cheltenham: Edward Elgar Publishing; 2014. pp. 51-65

[41] Jonsen K, Tatli A, Özbilgin MF, Bell MP. The tragedy of the uncommons: Reframing workforce diversity. Human Relations. 2013;66(2):271-294. DOI: 10.1177/0018726712466575

[42] Björkman I, Fey CF, Park HJ. Institutional theory and MNC subsidiary HRM practices: Evidence from a three-country study. Journal of International Business Studies. 2007; 38(3):430-446. DOI: $10.1057 /$ palgrave.jibs.8400267 
[43] Guthrie JP. High-involvement work practices, turnover, and productivity: Evidence from New Zealand. The Academy of Management Journal. 2001;44(1). DOI: 180-90. DOI: $10.2307 / 3069345$

[44] Huselid M. The impact of human resource management practices on Tunover, productivity, and corporate financial performance. Academy of Management Journal. 1995; 38(3):635-672. DOI: 10.2307/256741

[45] Macduffie JP. Human resource bundles and manufacturing performance: Organizational logic and flexible production systems in the world auto industry. Industrial and Labor Relations Review. 1995;48(2):197-221. DOI: 10.2307/2524483

[46] Buckley PJ, Horn SA. Japanese multinational enterprises in China: Successful adaptation of marketing strategies. Long Range Planning. 2009;42(4):495-517. DOI: 10.1016/j. lrp.2009.06.006

[47] Stiles P. The changing nature of the Japanese business system and its impact on Asia. Long Range Planning. 2009;42(4):427-438. DOI: 10.1016/j.lrp.2009.07.002

[48] Stavrou ET, Brewster C, Charalambous C. Human resource management and firm performance in Europe through the lens of business systems: Best fit, best practice or both? The International Journal of Human Resource Management. 2010;21(7):933-962. DOI: $10.1080 / 09585191003783371$

[49] Pudelko M. The end of Japanese-style management? Long Range Planning. 2009;42(4):439462. DOI: 10.1016/j.lrp.2009.04.001

[50] Ralston DA. The crossvergence perspective: Reflections and projections. Journal of International Business Studies. 2008;39(1):27-40. DOI: 10.1057/palgrave.jibs.8400333

[51] Aycan Z. The interplay between cultural and institutional/structural contingencies in human resource management practices. The International Journal of Human Resource Management. 2005;16(7):1083-1119. DOI: 10.1080/09585190500143956

[52] Gerhart B, Fang M. National culture and human resource management: Assumptions and evidence. The International Journal of Human Resource Management. 2005;16(6):971986. DOI: $10.1080 / 09585190500120772$

[53] Morgan G, Whitley R, Moen E. Changing Capitalisms?: Internationalization, Institutional Change, and Systems of Economic Organization. New York, USA: Oxford University Press; 2005

[54] Amable B. The Diversity of Modern Capitalism. Oxford: OUP; 2003

[55] Kang WI, Gaston F. Where are they going? Case of British and Japanese human resource management. Journal of Asia Business Studies. 2017;11(3):296-322. DOI: 10.1108/JABS-072015-0111

[56] Hasegawa H, Noronha C. Asian Business and Management: Theory, Practice and Perspectives. UK: Palgrave Macmillan; 2009 
[57] Chong D. Rational Lives: Norms and Values in Politics and Society. USA: University of Chicago Press; 2000

[58] North DC. Institutions, Institutional Change and Economic Performance. Cambridge, UK: Cambridge University Press; 1990

[59] Sako M. Shifting Boundaries of the Firm. Oxford: Oxford University Press; 2008

[60] Ignjatovic M, Sveltic I. European HRM clusters. Estonian Business Review. Autumn. 2003;(17):25-39. ISSN-1406-0264

[61] Hellmann UK. Delivers the chance for company's talent to sparkle: Development program for managers of the future. Human Resource Management International Digest. 2009;17(2):27-29. DOI: 108/09670730910940267

[62] Why cultural change is perfectly natural: In the long run, good habits can breed success. Human Resource Management International Digest. 2009;17(3):23-26. DOI: 10.1108/ 09670730910953371

[63] Carney M, Gedajlovic E, Yang X. Varieties of Asian capitalism: Toward an institutional theory of Asian enterprise. Asia Pacific Journal of Management. 2009;26(3):361-380. DOI: 10.1007/s10490-009-9139-2

[64] Preuss L, Haunschild A, Matten D. The rise of CSR: Implications for HRM and employee representation. The International Journal of Human Resource Management. 2009;20(4): 953-973. DOI: 10.1080/09585190902770893

[65] Zhao L. Convergence of east-west business management philosophy: The significant development of Chinese CSR theory and practices. In: Eweje G, editor. Corporate Social Responsibility and Sustainability: Emerging Trends in Developing Economies. Critical Studies on Corporate Responsibility, Governance and Sustainability. Vol. 8. Bingley, UK: Emerald Publishing; 2014. pp. 79-115. DOI: 10.1108/S2043-905920140000008007

[66] Tayeb M. Japanese managers and British culture: A comparative case study. The Inter national Journal of Human Resource Management. 1994;5(1):145-166. DOI: 10.1080/095 85199400000008

[67] Black JS, Morrison AJ. Sunset in the Land of the Rising Sun: Why Japanese Multinational Corporations will Struggle in the Global Future. Hampshire, UK: Palgrave Macmillan; 2010

[68] Eisenhardt KM. Building theories from case study research. The Academy of Management Review. 1989;14(4):532-550. DOI: 10.2307/258557

[69] Eisenhardt KM, Graebner ME. Theory building from cases: Opportunities and challenges. Academy of Management Journal. 2007;50(1):25-32. DOI: 10.5465/AMJ.2007.24160888

[70] Chad P. Processes of a case study methodology for postgraduate research in marketing. European Journal of Marketing. 1998;32(9/10):785-802. DOI: 10.1108/03090569810232237

[71] Wallis E, Stuart M, Greenwood I. Learners of the workplace unite!': An empirical examination of the UK trade union learning representative initiative. Work, Employment and Society. 2005;19(2):283-304. DOI: 10.1177/0950017005053174 
[72] Matsuzuka Y. Changes in the Permanent Employment System in Japan: Between 1982 and 1997. New York, USA: Routledge; 2002

[73] Salsberg B, Chandler C, Chhor H. Reimagining Japan. San Francisco: VIZ Media LLC; 2011

[74] Sako M, Satō H. Japanese Labour and Management in Transition: Diversity, Flexibility and Participation. London: Routledge; 1997

[75] Tulder R, Zwart A. International Business-Society Management. New York: Routledge; 2006

[76] Nikkei Weekly. 2011, September

[77] Labor Situation in Japan and Its Analysis: Detailed Exposition 2014/2015. The Japan Institute for Labour Policy and Training (JILPT); 2015. Available at: www.jil.go.jp/english/lsj/detailed/2014-2015.html

[78] Keizer AB. Non-regular employment in Japan: Continued and renewed dualities. Work, Employment and Society. 2008;22(3):407-425. DOI: 10.1177/0950017008093478

[79] Suzuki H. Employment relations in Japan: Recent changes under global competition and recession. Journal of Industrial Relations. 2010;52(3):387-401. DOI: 10.1177/ 0022185610365647

[80] Labor Situation in Japan and Analysis 2004/2005. Tokyo: Japan Institute for Labour Policy and Training (JILPT); 2004

[81] Nikkei Weekly. 2011, 29 August

[82] Adhikari DR, Budhwar P, Hirasawa K. Changing employment relation systems in Japan: Cases of the Mitsubishi chemical group and the Federation of Shinkin Banks. The International Journal of Human Resource Management. 2010;21(13):2414-2437. DOI: 10.1080/09585192.2010.516593

[83] Dore R. Flexible rigidities: Industrial policy and structural adjustment in the Japanese Economy, 1970-1980. Stanford: Stanford University Press; 1986

[84] Sako M. Price, Quality and Trust: Inter-Firm Relations in Britain and Japan. Cambridge, UK: Cambridge University Press; 1992

[85] Westney DE, Program MJ. The Japanese Business System: Key Features and Prospects for Change: MIT Japan Program. USA: Center for International Studies, Massachusetts Institute of Technology; 1996

[86] Whitley R. Business Systems and Organizational Capabilities. Oxford: Oxford University Press; 2007 
